\title{
Cryptic terminal rearrangement of chromosome 22q13.32 detected by FISH in two unrelated patients
}

\author{
Kimberly F Doheny, Heather E McDermid, Karen Harum, George H Thomas, \\ Gerald V Raymond
}

Departments of Pediatrics, The Johns Hopkins University School of Medicine, Baltimore, MD, USA K F Doheny

K Harum

G H Thomas

Department of Neurology, The Johns Hopkins University School of Medicine, Baltimore, MD, USA G V Raymond

Kennedy Krieger Institute, Baltimore, MD, USA

K F Doheny

K Harum

G H Thomas

G V Raymond

Department of Biological Sciences, University of Alberta, Edmonton, Canada H E McDermid

Correspondence to: Dr Doheny, Center for Inherited Disease Research, Johns Hopkins Bayview Campus, Triad Technology Center, Suite 2000,

Baltimore, MD 21224, USA.

Received 24 June 1996 Revised version accepted for publication 13 March 1997

\begin{abstract}
Two unrelated patients with cryptic subtelomeric deletions of 22q13.3 were identified using FISH with the commercially available Oncor probe, D22S39. Proband 1 was found to have a derivative chromosome 22 resulting from the unbalanced segregation of a $t(1 ; 22)(q 44 ; q 13.32)$ in her mother. Additional FISH analysis of proband 1 and her mother placed the breakpoint on chromosome 22 in this family proximal to D22S55 and D22S39 and distal to D22S45. We have mapped D22S39 to within $170 \mathrm{~kb}$ of D22S21 using pulsed field gel electrophoresis. D22S21 is genetically mapped between D22S55 and D22S45. These data indicate that the deletion in proband 1 is smaller than in eight of nine reported del(22)(q13.3) patients. Probands 1 and 2 share features of hypotonia, developmental delay, and expressive language delay, also seen in previously reported $\operatorname{del}(22)(q 13.3)$ patients, although proband 1 appears to be more mildly affected. Proband 1 is also trisomic for the region 1 q44 $\rightarrow$ qter. This very small duplication has been previously reported only once and the patient had idiopathic mental retardation. This is the first report where 22q13.3 terminal deletion patients have been identified through the use of FISH, and the first report of a deletion of this region occurring because of missegregation of a parental balanced cryptic translocation. We feel that investigation of the frequency of $\operatorname{del}(22)(q 13.3)$ in the idiopathic mentally retarded population is warranted and may be aided by the ability to use a commercially available probe (D22S39), which is already currently in use in a large number of cytogenetic laboratories.

$(\Im$ Med Genet 1997;34:640-644)
\end{abstract}

Keywords: del(22)(q13.3); cryptic subtelomeric rearrangement; idiopathic mental retardation; D22S39

It has been estimated that at least $6 \%$ of idiopathic mental retardation is caused by cryptic subtelomeric chromosome rearrangements. ${ }^{1}$ The recent description of several patients with deletions of the subtelomeric region of the long arm of chromosome 22 suggests that rearrangements of this region may account for an important subset of this group of patients. To date, we are aware of at least 15 patients reported to have de novo subtelomeric deletions involving 22q13.3. Thirteen patients were identified through high resolution cytogenetics, ${ }^{23}$ while two were identified with Southern blot screening. ${ }^{1}$

We now describe the use of a widely available probe for the detection of this group of patients by FISH analysis. Using the commercially available Oncor probe (D22S39), included as a control with the probe (D22S75) for DiGeorge syndrome, we have recently identified two additional unrelated patients with deletions of 22q13.3.

This is the first report where $22 \mathrm{q} 13.3$ terminal deletion patients have been identified through the use of FISH, and the first report of a deletion of this region occurring because of missegregation of a parental balanced cryptic translocation.

\section{Subjects and methods}

CLINICAL REPORTS

Case 1 (proband 1) presented at 22 months of age for evaluation of developmental delay. She was the $2892 \mathrm{~g}$ product of a 37 week gestation to a 35 year old G2, P0 woman. Concern was first raised at 4 months when she was not rolling over, but she has made developmental progress. She walked at 16 months of age. At 22 months, she had three words, but had appropriate receptive language. At 2 years of age, her weight was $12.6 \mathrm{~kg}$ (50th centile), length $84 \mathrm{~cm}$ (25th centile), and head circumference was $48 \mathrm{~cm}$ (50th centile). She had bilateral epicanthic folds, a haemangioma on her forehead, and full cheeks (fig 1). She had a small umbilical hernia. She was moderately hypotonic, walked with a waddling gait, and was clumsy, but no ataxia was noted. Reflexes were present and toes were flexor. An MRI performed at 30 months of age was normal. The family history was non-contributory except for a seven year period of infertility in her parents.

Case 2 (proband 2) is a 13 month old girl who presented with developmental delay. She was the $2665 \mathrm{~g}$ (10th centile) product of a term gestation born by vaginal delivery to a 21 year old G2, P1 woman. Fetal movements were not noted until 7 months and were reported to be less vigorous than the previous pregnancy. In the newborn period, she was noted to have a small ventricular septal defect which closed spontaneously, feeding difficulties, and slow 


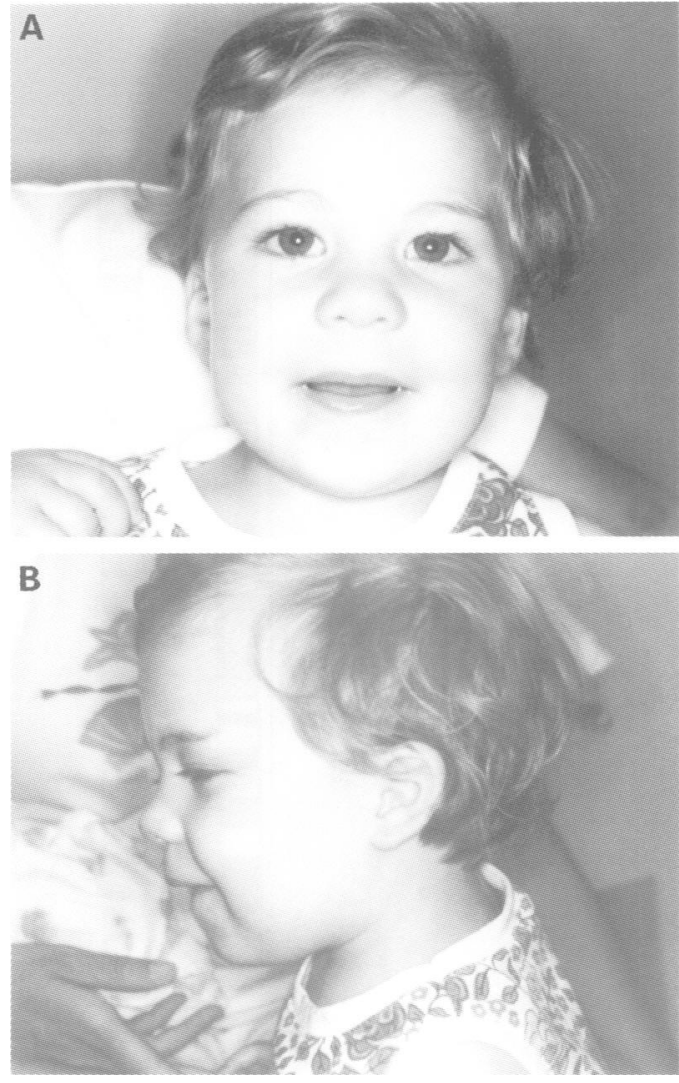

Figure 1 (A) Front view and (B) side view of proband 1 aged 22 months. Note epicanthic folds, normal head shape, normally set and formed ears, and relatively normal appearance. (Photographs reproduced with permission.)

weight gain. She has vesicoureteral reflux without anatomical abnormality. Developmentally, she sat at 11 months, pulled to stand at 12 months, and babbled but did not have any words. On physical examination, her length was $79.5 \mathrm{~cm}$ (95th centile), weight was $9.8 \mathrm{~kg}$ (50th centile), and her head circumference was 45.8 $\mathrm{cm}$ (50th centile). There were no unusual facial features. She had a $6 \times 3 \mathrm{~cm}$ irregular macule on the medial surface of her leg. She had decreased tone, but was able to sit unsupported and stand holding on. Reflexes were present and normal except for clonus at the ankles. An MRI showed mild delay in myelination with some thinning of the corpus callosum. The family history was unremarkable.

CYTOGENETIC AND MOLECULAR STUDIES

Peripheral blood lymphocytes were initially examined by $\mathrm{G}$ banded chromosome analysis. Fibroblast lines from patient FB and his parents, previously reported by Phelan et al, ${ }^{11}$ were obtained from Dr Harold Taylor at the Greenwood Genetics Center, Greenwood, South Carolina. Metaphase preparations were $\mathrm{G}$ banded with the trypsin method and stained with Wright stain. ${ }^{4}$ FISH studies were done using D22S75, DiGeorge chromosome region (DGCR) probe with D22S39 chromosome 22 control probe, obtained from Oncor, Gaithersburg, MD (Cat No P5140-DIG). Hybridisation was carried out according to the manufacturer's recommendations using the rapid wash conditions and no signal amplification.

FISH studies carried out to define the extent of missing chromosome 22 material were done using yeast strains containing YACs M412H3 and M120E4 obtained from Dr Callum Bell at The Children's Hospital of Philadelphia. ${ }^{5}$ In addition, a 14/22 alpha satellite probe (Oncor, Inc) was used to identify the chromosomes 22 . Total yeast genomic DNA was labelled with biotin-14-dATP using a BioNick labelling system (BRL) and FISH was performed according to the method described by Pinkel et $a l^{67}$ with some modifications: $1 \mu \mathrm{g}$ of labelled yeast genomic DNA and $5 \mu \mathrm{g}$ Cot- 1 DNA were used per hybridisation, slides were denatured at $70^{\circ} \mathrm{C}$ in $70 \%$ formamide, $2 \times \mathrm{SSC}, \mathrm{pH} 7.0$, and hybridised for 48 hours at $37^{\circ} \mathrm{C}$; posthybridisation wash was $50 \%$ formamide, $2 \times \mathrm{SSC}$, pH 7.0 , at $40^{\circ} \mathrm{C}$.

Pulsed field gel electrophoresis (PFGE) was performed using a CHEF-DRII apparatus (BioRad). Cells from three subjects normal for the 22q13.3 region were embedded in agarose and processed as previously described. ${ }^{8}$ DNA was digested with $N o t \mathrm{I}, N r u \mathrm{I}, A s c \mathrm{I}$, or BsiWI and separated by PFGE at $150 \mathrm{~V}$ using a 120 second switch time for 22 hours followed by a 180 second switch time for 22 hours. The resulting blot was probed with the clone for D22S21. The blot was then stripped of signal and reprobed with the clone for D22S39.

\section{Results}

CASE 1

Cytogenetic analysis was performed on proband 1 as well as FISH analysis to rule out Prader-Willi/Angelman syndrome because of her hypotonia. No deletion of D15S10 or SNRPN was found. A subtelomeric abnormality in the terminal band of chromosome 22q was suspected after routine cytogenetic analysis (band level 650) but the alteration in the $G$ banding pattern was sufficiently subtle that without additional confirmation the exact nature of the alteration could not be established (fig 2A). To define the nature of the suspected abnormality more precisely, we carried out FISH analysis using the Oncor DiGeorge probe containing the control probe (D22S39) localised to the subtelomeric region (q13.3) of chromosome 22. Hybridisation of this cosmid mixture to metaphase spreads from proband 1 showed a deletion of cosmid D22S39. Two signals (proximal and distal) were seen on one chromosome 22 and only one signal (proximal) on the other chromosome 22 in 20/20 metaphase spreads examined (fig $3 \mathrm{~A}$ ). This result together with the $G$ banding interpretation resulted in the karyotype of proband 1 being originally reported as 46,XX,del(22)(q13.33).ish del(22)(q13.3q13.3) (D22S39-) or 46,XX, $\operatorname{add}(22)$ (q13.32).ish $\operatorname{del}(22)$ (q13.3q13.3)(D22S39-). FISH analysis of metaphase spreads from the mother of proband 1 with the DGCR probe mixture showed two signals on one chromosome 22, one signal (proximal) on the other chromosome 22 , as well as one signal at either the $p$ or q terminus of chromosome 1 (fig 3B). Thus, the mother of proband 1 was carrying a balanced cryptic translocation involving the D22S39 cosmid region. G banding analysis showed that the translocation involved an 
A

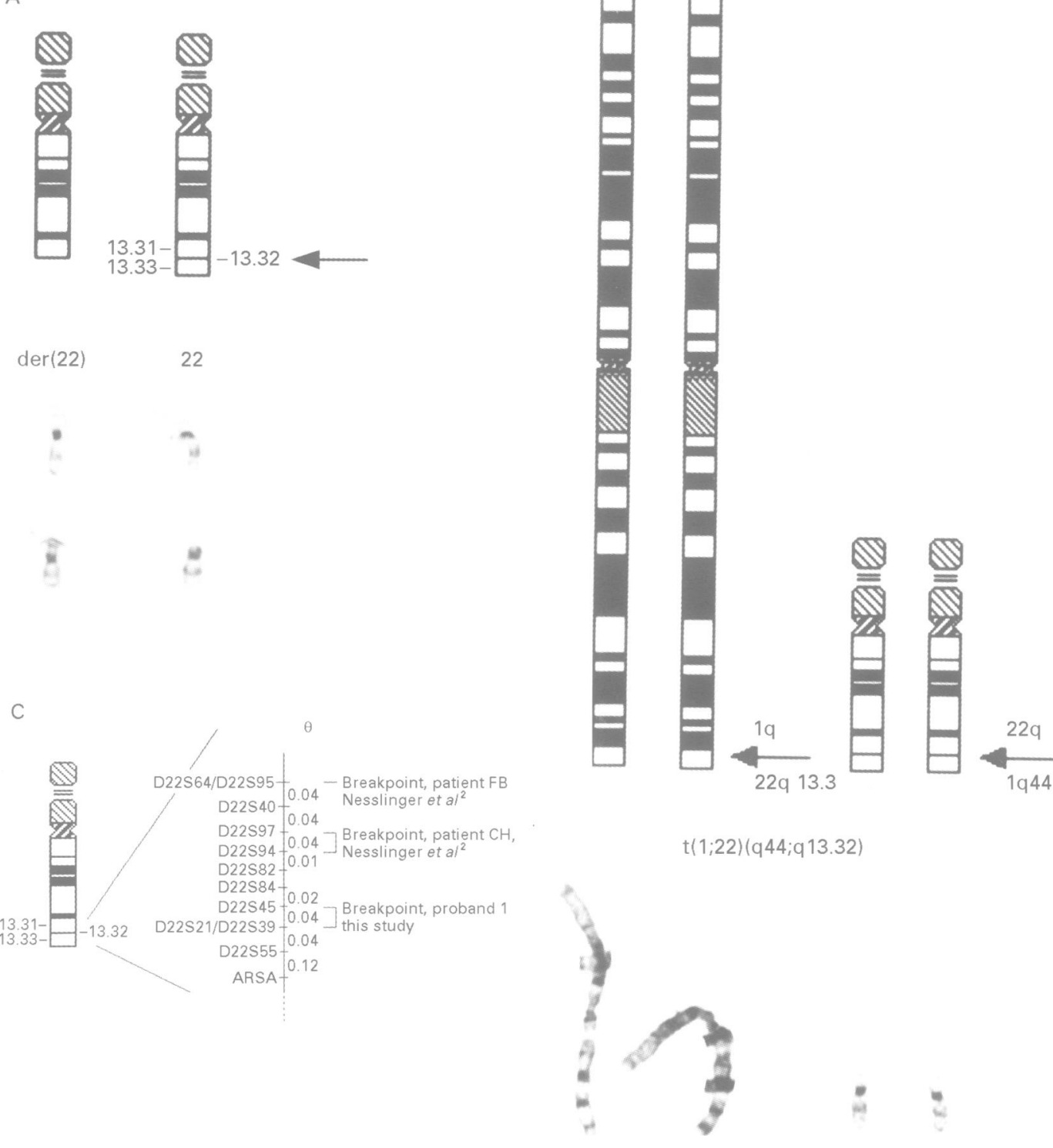

Figure 2 (A) Idiogram showing region lost in der(22) chromosome and partial karyotype of chromosomes 22 seen in proband 1 (top set) and proband 2 (bottom set). (B) Idiogram and partial karyotype of $t(1 ; 22)(q 44 ; q 13.32)$ seen in mother of proband 1. (C) Map of loci in subtelomeric region of chromosome $22 q$ with recombination fractions $(\theta)$ indicated. ${ }^{10} A$ physical map of chromosome 22 is reported in Collins et al. ${ }^{19}$ D22S39 is placed with D22S21 as a result of our mapping data. Deletion breakpoints are indicated for proband 1, this report, and patients $C H$ and FB of Nesslinger et al. ${ }^{2}$ Patient $\mathrm{CH}$ carried the smallest deletion described in Nesslinger et al, ${ }^{2}$ thus indicating the previously defined critical region, and patient FB was probed with D22S39 as a positive control.

exchange of material from the termini of the long arms of one chromosome 1 and one chromosome 22, 46,XX,t $(1 ; 22)(\mathrm{q} 44 ; \mathrm{q} 13.32)$.ish $\mathrm{t}(1 ; 22)(\mathrm{D} 22 \mathrm{~S} 39+; \mathrm{D} 22 \mathrm{S39}$ ) (fig 2B). Her daughter, proband 1 , inherited only her derivative chromosome 22 resulting in monosomy for the region $22 \mathrm{q} 13.32$ to 22 qter and trisomy for $1 \mathrm{q} 44$. The karyotype of proband 1 was revised in light of this finding to $46, \mathrm{XX}, \operatorname{der}(22) \mathrm{t}(1 ; 22)$ (q44;q13.32)mat.ish $\operatorname{der}(22) t(1 ; 22)$ (D22S39-; D22S39-). The father of proband 1 and one maternal aunt were found to have normal karyotypes.

Additional FISH analysis with chromosome 22q terminal YAC probes further localised the breakpoint for this rearrangement. Hybridisation with YAC M412H3 (which contains the DNA marker D22S55) resulted in a fluores- cent signal on only one chromosome 22 qter in metaphase spreads from proband 1 . When metaphase spreads from her mother were assayed, a signal was seen on one chromosome 22qter as well as at the terminal end of one chromosome 1 (fig 3C). This result localises the marker D22S55 distal to the breakpoint in this family (fig 2C). Hybridisation with YAC M120E4 (which contains marker D22S45) resulted in fluorescent signals at the terminus of both chromosomes 22 in metaphase spreads from proband 1 and her mother (fig 3D). This result localises the marker D22S45 proximal to the breakpoint in this family (fig $2 \mathrm{C}$ ).

\section{CASE 2}

Routine cytogenetic analysis was performed on proband 2. A subtelomeric deletion in the ter- 

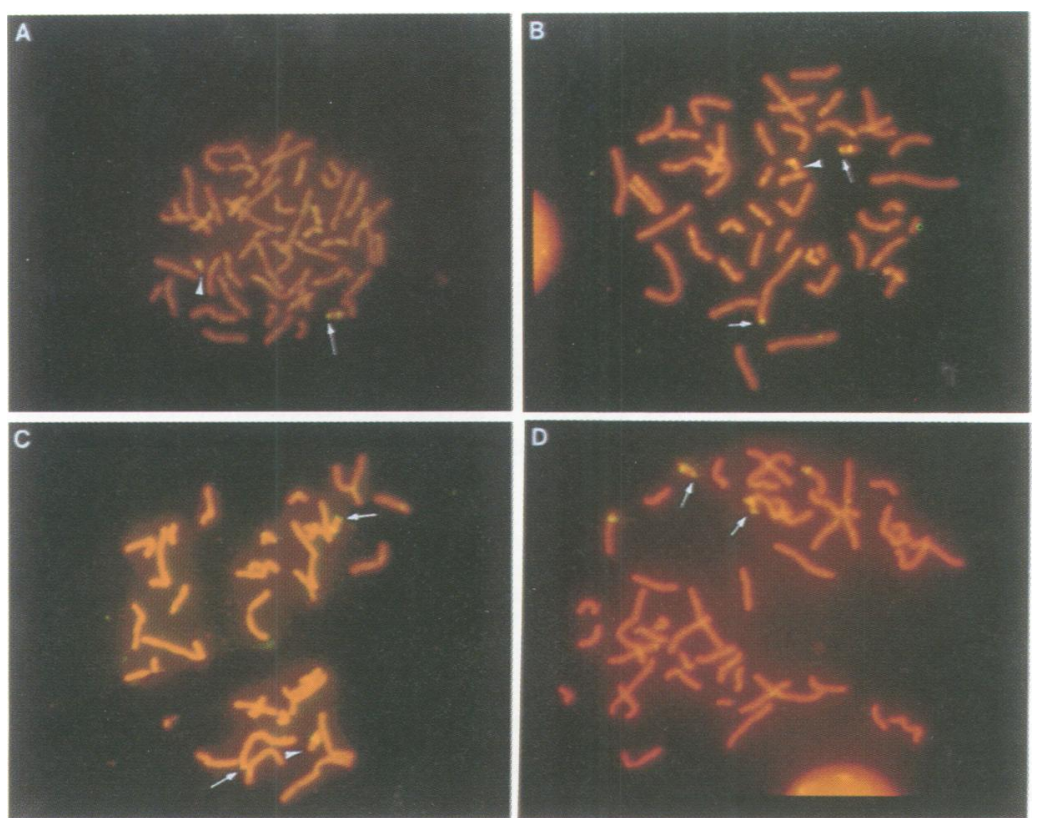

Figure 3 (A) FISH analysis of representative metaphase spread from proband 2 showing deletion of D22S39. Proximal signals indicate hybridisation of D22S75 and distal signal (single arrow) indicates hybridisation of D22S39. Arrowhead indicates absence of signal on distal end of one chromosome 22. Identical results were seen with metaphase spreads from proband 1. (B) FISH analysis of representative metaphase spread from the mother of proband 1. (B) FISH analysis of representative metaphase spread from the mother of 1 showing translocation of D22S39 to the terminal end of one chromosome 1. D22S75 hybridisation to the proximal region of chromosomes 22 is seen, D22S39 hybridisation to the distal region of one chromosome 22 and to the terminus of one chromosome 1 is indicated by two arrows. Arrowhead indicates absence of signal on distal end of one chromosome 22. (C) FISH analysis of representative metaphase spread from the mother of proband 1 showing hybridisation pattern of YAC M412H3 (D22S55) similar to D22S39 placing the chromosome 22 breakpoint proximal to D22S55. Hybridisation of a $14 / 22$ alpha satellite probe is seen, hybridisation of $Y A C M 412 H 3$ is indicated by arrows. Arrowhead indicates absence of signal on distal end of one chromosome 22. (D) FISH analysis of representative metaphase spread from the mother of proband 1 using YAC M120E4 (D22S45) placing the breakpoint distal to D22S45. Hybridisation of a 14/22 alpha satellite probe is seen. Arrows indicate hybridisation of YAC M120E4 to the distal ends of both the normal chromosome 22 and the derivative chromosome 22.

minal band of chromosome $22 \mathrm{q}$ was suspected in metaphase spreads examined after microscopic analysis ( 550 band level), but as in case 1 the alteration in the $\mathrm{G}$ banding pattern was subtle. Hybridisation of the DGCR cosmid mixture to metaphase spreads from proband 2 showed a deletion of cosmid D22S39 in 50/50

Table 1 Features of $\operatorname{del}(22)$ ( $(13.3)$ patients

\begin{tabular}{|c|c|c|c|}
\hline Features & $\begin{array}{l}\text { Patients described in } \\
\text { refs } 1,2 \text {, and } 3^{*}\end{array}$ & $\begin{array}{l}\text { Proband } 1 \\
\text { (this study) }\end{array}$ & Proband 2 (this study) \\
\hline \multicolumn{4}{|l|}{$\begin{array}{l}\text { Height and weight } \\
\text { appropriate for } \\
\text { gestational age }\end{array}$} \\
\hline $\begin{array}{l}\text { (not IUGR) } \\
\text { Hypotonia }\end{array}$ & $\begin{array}{l}12 / 12 \\
10 / 13\end{array}$ & $\begin{array}{l}\text { Yes } \\
\text { Yes }\end{array}$ & $\begin{array}{l}\text { Yes } \\
\text { Yes }\end{array}$ \\
\hline Developmental delay & $\begin{array}{l}10 / 13 \\
15 / 15\end{array}$ & $\begin{array}{l}\text { Yes } \\
\text { Yes }\end{array}$ & $\begin{array}{l}\text { Yes } \\
\text { Yes }\end{array}$ \\
\hline Delay of gross motor & & & \\
\hline $\begin{array}{l}\text { milestones } \\
\text { Age at 1st step: }\end{array}$ & $13 / 15$ & Yes & Yes \\
\hline 20.5-39 months & 9 & 16 months & Not walking at 13 months \\
\hline $\begin{array}{l}\text { Expressive language } \\
\text { status }\end{array}$ & $\begin{array}{l}\text { Delay }(4) \\
\text { No words/babbles }(7) \\
<10 \text { words (2) } \\
\text { Too young to ascertain } \\
\text { (2) }\end{array}$ & $<10$ words at $21 / 2 y$ & Babbles at 13 months \\
\hline $\begin{array}{l}\text { Mild dilatation of } \\
\text { cerebral ventricles }\end{array}$ & $5 / 12$ & No & No \\
\hline Seizures & $3 / 12$ & No & No \\
\hline Dolichocephaly & $7 / 12$ & No & No \\
\hline Ptosis & $4 / 12$ & No & No \\
\hline Epicanthic folds & $8 / 12$ & Yes & No \\
\hline Dysplastic ears & $10 / 13$ & No & No \\
\hline Tall stature & $3 / 14$ & No & $95 \%$ \\
\hline Vesicoureteral reflux & $1+$ & No & Yes \\
\hline
\end{tabular}

^Number in denominator reflects whether the feature was mentioned in the report, please note that patient $A$ in Zwaigenbaum $e t a l^{\beta}$ is the same as $Q M$ in Nesslinger $e t a l .^{2}$ tHerman et al..$^{16}$ metaphase spreads examined. This result, together with the $\mathrm{G}$ banding interpretation, resulted in the karyotype $46, \mathrm{XX}, \operatorname{del}(22)$ (q13.32).ish $\operatorname{del}(22)$ (q13.3q13.3)(D22S39-) or $46, \mathrm{XX}, \operatorname{add}(22)$ (q13.32).ish $\operatorname{del}(22)$ (q13.3 q13.3)(D22S39-) (fig 3A). The parents of proband 2 are unavailable for study.

FISH analysis was performed with chromosome 22q terminal YAC probes. Hybridisation with either YAC $412 \mathrm{H} 3$ (which contains the DNA marker D22S55) or YAC 120E4 (encompassing D22S45) resulted in a fluorescent signal on only one chromosome 22qter in metaphase spreads from proband 2 (data not shown). Thus the breakpoint in this subject is located proximal to both of these loci.

\section{MAPPING OF D22S39}

D22S39 (H17) has been placed into the last somatic cell hybrid panel "bin" of chromosome 22 (bin22). ' Using pulsed field gel electrophoresis we further localised this marker to not more than $170 \mathrm{~kb}$ from the probe for D22S21 (W13E) (fig 2C). Digestion of normal DNA with $N o t \mathrm{I}, N r u \mathrm{I}, A s c \mathrm{I}$, and $B s i$ WI gave identical bands when probed with clones for D22S39 or D22S21 (data not shown). The smallest band detected by both probes was $170 \mathrm{~kb}$ (NruI digest). D22S21 has been genetically mapped between D22S45 and D22S55 ${ }^{10}$ (fig 2C).

\section{FISH ANALYSIS OF A PREVIOUSLY REPORTED}

DEL(22)(q13.3) PATIENT USING D22S39

As further evidence for the value of D22S39 in FISH analysis to detect 22qter deletion patients, we assayed metaphase spreads from FB, a previously described de novo $\operatorname{del}(22)$ (q13.31) patient, and his parents, ${ }^{11}$ and verified that only one distal $22 \mathrm{q}$ hybridisation signal was seen in FB and two signals were seen in both of his parents (data not shown). The breakpoint in this patient had been previously localised using dosage and RFLP analysis between D22S64 and D22S95 (fig 2C).

\section{Discussion}

The clinical features in these two probands with monosomy for 22q13.32 $\rightarrow 22$ qter are similar to those described in previously reported cases of 22q13.3 deletions ${ }^{1-3}$ (table 1). Proband 1 appears to be more mildly affected in that she walked earlier (16 months), speaks a few words, and does not have any dysmorphic features other than epicanthic folds (table 1). This would seem to correlate with the fact that her breakpoint is located between D22S45 and D22S39, distal to the breakpoints defined for the patients described in Nesslinger et al (fig 2C). Enzyme studies measuring arylsulphatase A (ARSA) activities in proband 1 and her parents were consistent with deletion of this locus in proband 1 (data not shown). A pulse field gel electrophoresis map of 22q13.3 (H McDermid, unpublished data) gives a rough estimate (a gap exists between H91 and ARSA which cannot be measured) of a distance of over 1800 $\mathrm{kb}$ from D22S39/D22S21 to the telomere. The only reported 22qter deletion patient (NT) with a smaller deletion than proband 1 is reported to be non-dysmorphic with normal 
motor milestones, mild mental retardation, and first words at the age of 4 years. ${ }^{1}$ His deletion has been reported to be approximately $120 \mathrm{~kb}$ in size, with the breakpoint located distal to ARSA. ${ }^{12}{ }^{13}$ Proband 1, in addition to monosomy for $22 \mathrm{q} 13.32 \rightarrow 22 \mathrm{qter}$ is trisomic for the region 1q44 $\rightarrow$ 1qter. A review of published reports identified only one previous report of $\operatorname{dup}(1)(\mathrm{q} 44)$ in which the proband had idiopathic mental retardation with no associated malformations. ${ }^{14} \mathrm{~A}$ review of patients carrying a duplication of the distal third of chromosome 1 (breakpoints from q23-q44) showed no features in common with proband 1 other than developmental delay. ${ }^{15}$

Proband 2 is still too young to ascertain the degree of severity of her language and motor delay. The general clinical impression of her progress indicates that she is more severely affected than proband 1 , as would be expected from the result that her chromosome 22 breakpoint is located proximal to D22S45. One unusual feature seen in proband 2, vesicoureteral reflux, has also been seen in one previously described patient with $\operatorname{del}(22)(\mathrm{q} 13.31) .^{16}$

The evidence for deletion of 22q13.3 being the cause, and not an unrelated, relatively common polymorphism, includes controls published by Flint et al. ${ }^{1}$ They studied by Southern analysis 186 nuclear families and 80 meioses from CEPH pedigrees for deletions, as well as 3000 unrelated subjects, for duplications of this region and identified no person aneusomic for the terminal region of chromosome 22q. Our internal laboratory controls include 97 patients for which we have used the DiGeorge chromosome region Oncor probe with FISH analysis to rule out microdeletions of the $22 \mathrm{q} 11.2$ region. No-one in this patient population ( $r$ /o DiGeorge syndrome, velocardiofacial syndrome, and isolated conotruncal heart defects) has been deleted for the distal marker cosmid D22S39, as was seen in our two probands.

We feel that investigation of the frequency of $\operatorname{del}(22)(q 13.3)$ in the idiopathic mentally retarded population is warranted given the fact that two of the three subjects identified in the study by Flint $e t a l^{1}$ had 22qter deletions and the recent identification of the two probands described here. The ability to use a commercially available probe (D22S39), which is already currently in use in a large number of cytogenetic laboratories, as an assay for patients with subtelomeric deletions of chromosome 22 will hopefully facilitate this investigation. A unique $22 q$ telomere specific FISH probe has also been recently isolated and described by Ning et al. ${ }^{17}$

In light of our experience with these two cases, when a very subtle deletion is suspected after G banding analysis, we suggest that currently available FISH probes could be useful in defining the abnormality. Similar to the cases described here, we have also recently identified a "cryptic" de novo 20p terminal deletion (suspected after G banding analysis) with a subtelomeric FISH probe in an idiopathic mentally retarded subject. A com- plete set of subtelomeric chromosome specific probes has recently been described. ${ }^{18}$ When such a set is available in a multicolour FISH format, screening of the idiopathic mental retardation population will hopefully aid in the rapid identification of a cause for developmental delay in a subset of these subjects. As shown by the family of proband 1 , there is then potential for the identification of a cryptic familial terminal rearrangement in such cases. The recurrence risk for another affected child in such families is obviously greatly increased.

We would like to thank all the members of the Kennedy Krieger Institute Cytogenetics Laboratory for their technical expertise in the preparation of these cases, especially Shirley Perdue and Susan Morsey for the identification of the subtle aberrant G basan Morsey for the identification of the subtle aberrant $G$ banding patterns in probands 1 and 2 . We would like to thank
Callum Bell for generously providing us with YACs and Forrest Callum Bell for generously providing us with YACs and Forrest
Spencer for the use of reagents and equipment. In addition, we would like to thank the family of proband 1 for allowing the publication of clinical photographs. KFD and GHT are partially supported by NICHD Mental Retardation Research Center Core Grant HD24061. A permanent cell line of proband 1, L95-1728, is available at Kennedy Krieger Institute, Baltimore, MD, through Dr G H Thomas.

1 Flint J, Wilkie AOM, Buckle VJ, Winter RM, Holland AJ, McDermid HE. The detection of subtelomeric chromosomal rearrangements in idiopathic mental retardation. Nat Genet 1995;9:132-9.

2 Nesslinger NJ, Gorski JL, Kurczynski TW, et al. Clinical, cytogenetic and molecular characterization of seven patients with deletions of chromosome 22q13.3. Am f Hum Genet 1994;54:464-72.

3 Zwaigenbaum L, Siegel-Bartelt J, Teshima I, Ho C. Two patients with 22q13.3 deletions have similar facies and developmental patterns. Am f Hum Genet 1990;47:A45.

4 Barch MJ, ed. The ACT cytogenetics laboratory manual. 2nd ed. New York: Raven Press, 1990:17-107, 149-205.

5 Bell CJ, Budarf ML, Nieuwenhuijsen BW, et al. Integration of physical, breakpoint and genetic maps of chromosome 22. Localization of 587 yeast artificial chromosomes with 238 mapped markers. Hum Mol Genet 1995;4:59-69.

6 Pinkel D, Straume T, Gray JW. Cytogenetic analysis using quantitative, high sensitivity, fluorescence hybridization. Proc Natl Acad Sci USA 1986;83:2934-8.

7 Pinkel D, Landegent J, Collins C, et al. Fluorescence in situ hybridization with human chromosome-specific libraries: detection of trisomy 21 and translocations of chromosome 4. Proc Natl Acad Sci USA 1988;85:9138-42.

$8 \mathrm{McDermid}$ HE, Budarf ML, Emanuel BS. Long-range map of human chromosome 22q11-22q12 between the lambda immunoglobulin locus and the Ewing sarcoma breakpoint. Genomics 1993;18:308-18.

9 Budarf JL, Eckman B, Michaud D, et al. Regional localization of over 300 loci on human chromosome 22 using a somatic cell hybrid mapping panel. Genomics 1996; 35:275-88

10 Dumanski JP, Carlbom E, Collins VP, et al. A map of 22 loci on human chromosome 22. Genomics 1991;11:709-19.

11 Phelan MC, Thomas GR, Saul RA, et al. Cytogenetic, biochemical, and molecular analyses of a $22 \mathrm{q} 13$ deletion. $\mathrm{Am}$ f Med Genet 1992;43:872-6.

12 Wong AC, Bell CJ, Dumanski JP, Budarf ML, McDermid HE. Molecular characterization of a microdeletion at 22q13.3. Am f Hum Genet 1995;57:A130.

13 Wong AC, Ning Y, Flint J, et al. Molecular characterization of a $130 \mathrm{~kb}$ terminal microdeletion at $22 \mathrm{q}$ in a child with mild mental retardation. Am f Hum Genet 1997;60:113-20.

14 Kessel E, Pfeiffer RA, Welling P. Translocation $22 / Y$ familiale et trisomie partielle autosomique chez une jeune fille. $\mathcal{F}$ iale et trisomie partielle autos

15 Johnson VP. Duplication of the distal part of the long arm of chromosome 1. Am f Med Genet 1991;39:258-69.

16 Herman GE, Greenberg F, Ledbetter DH. Multiple congenital anomaly/mental retardation (MCA/MR) syndrome with Goldenhar complex due to a terminal $\operatorname{del}(22 \mathrm{q})$. Am $\mathcal{F}$ Med Genet 1988;29:909-15.

17 Ning Y, Rosenberg M, Biesecker LG, Ledbetter DH. Isolation of the human chromosome $22 \mathrm{q}$ telomere and its applition of the human chromosome cation to detection of cryp

18 National Institutes of Health and Institute of Molecular Medicine Collaboration. A complete set of human telomeric probes and their clinical application. Nat Genet 1996;14:86-9.

19 Collins J, Cole CG, Smink LJ, et al. A high-density YAC contig map of human chromosome 22. Nature 1995;377: 367-79. 